\title{
Immune Thrombocytopenic Purpura as the Presenting Feature of Primary Small Bowel Adenocarcinoma
}

Eric R. Wiedower, DO, Seth Page, MD, Shawn Jackson, MD, and Elie Chalhoub, MD

Introduction

- Small bowel adenocarcinoma is a rare malignancy with only 6,969 cases reported annually in the US, accounting for approximately $2 \%$ of gastrointestinal tumors and less than $0.4 \%$ of all malignancies.

- Immune thrombocytopenic purpura (ITP) is a common hematological disorder with an incidence of two cases per 100,000 people. While ITP has many clinical manifestations, it uncommonly is the presenting feature of a malignancy.

\section{Case Presentation}

This is a 72-year-old female that presented with coffee-ground emesis and melanotic stools. The patient was found to be thrombocytopenic with a platelet count of $13 \mathrm{~K}$ in addition to acute blood loss anemia. She responded poorly to platelet transfusion.

\section{EGD shows large, fungating mass} present at level of duodenal bulb

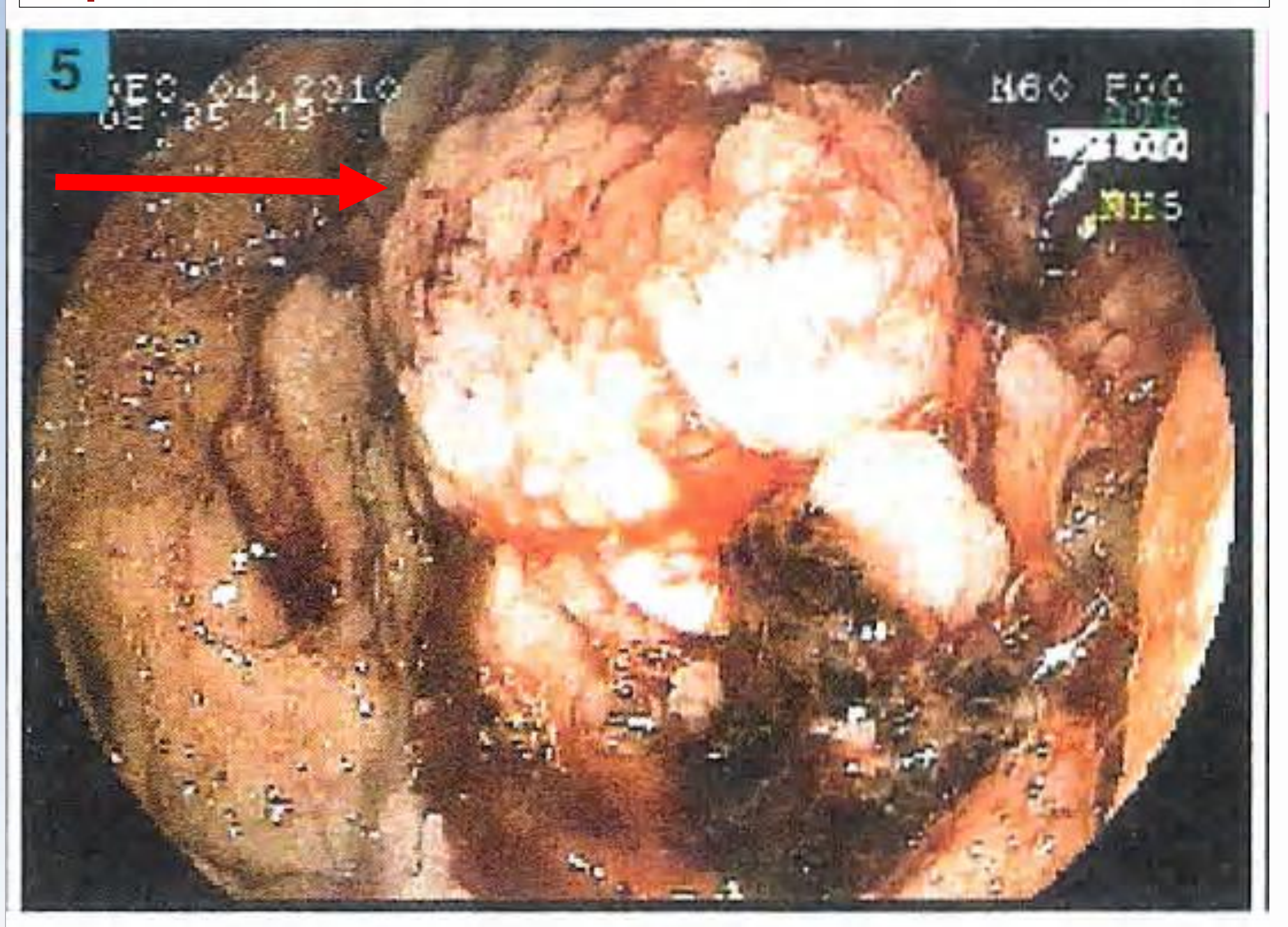

\section{Conclusions}

While more commonly associated with humoral malignancies, ITP can also manifest in presence of a solid tumor. An extensive review of the literature showed no case reports of ITP as the presenting feature of primary small bowel adenocarcinoma. The significance of ITP as a paraneoplastic syndrome for this malignancy is unknown. While no causal link can be made from the primary carcinoma in situ and her immune thrombocytopenia, certainly her severe thrombocytopenia directly resulted in the discovery of a rare small bowel tumor.

\section{References}

1. Abraham J, Gulley JL, Allegra CJ. Bethesda Handbook of Clinical Oncology. Philadelphia: Lippincott Williams \& Wilkins, 2005, pp. 147-151.

2. Bir A, Bshara W, George M, Fakih MG. Idiopathic Thrombocytopenic Purpura in a Newly Diagnosed Pancreatic Adenocarcinoma. J Pancreas 2006; 7(6):647-650.

3. Cines DB, Bussel JB, Liebman HA, Luning Prak ET. The ITP Syndrome: Pathogenic and Clinical Diversity. Blood 2009; 113(26);6511-6521.

4. Rodgers GP, Young NS. Bethesda Handbook of Clinical Hematology. Philadelphia: Wolters Kluwer Health/Lippincott William \& Wilkins, 2010, pp. 250-252.

\section{- Treated with IVIG and steroids}

Treated with IVIG and steroids empirically

- Platelets respond well with ITP treatment

- Completely resolved after 3 month steroid taper with no recurrence

Primary small bowel adenocarcinoma

- Discovered during EGD for hematemesis

- Biopsy confirmed diagnosis

- No sign of metastatic disease on CT scans

- Received proximal resection of duodenum

- Currently doing well

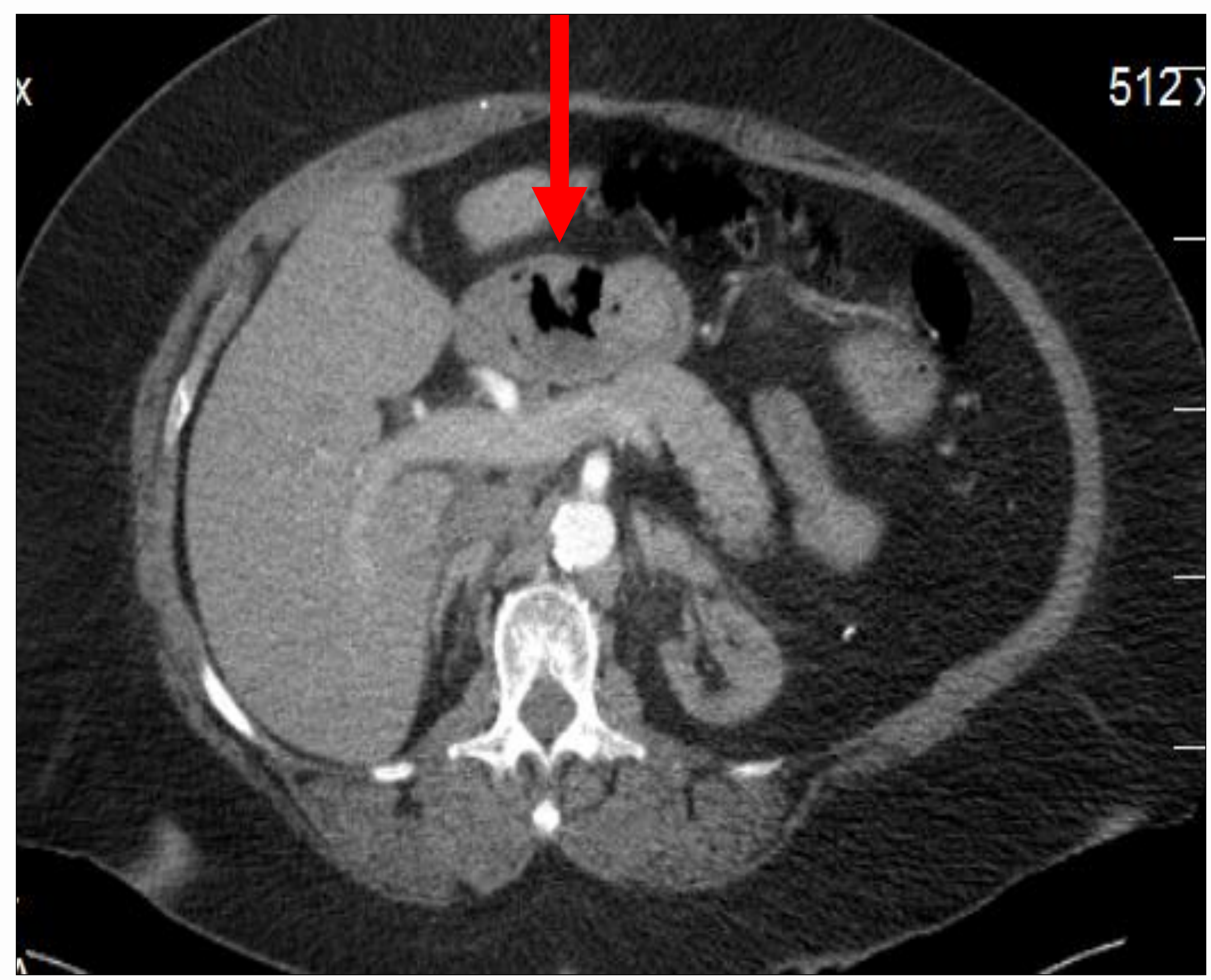

Duodenal mass present on abdominal CT scan

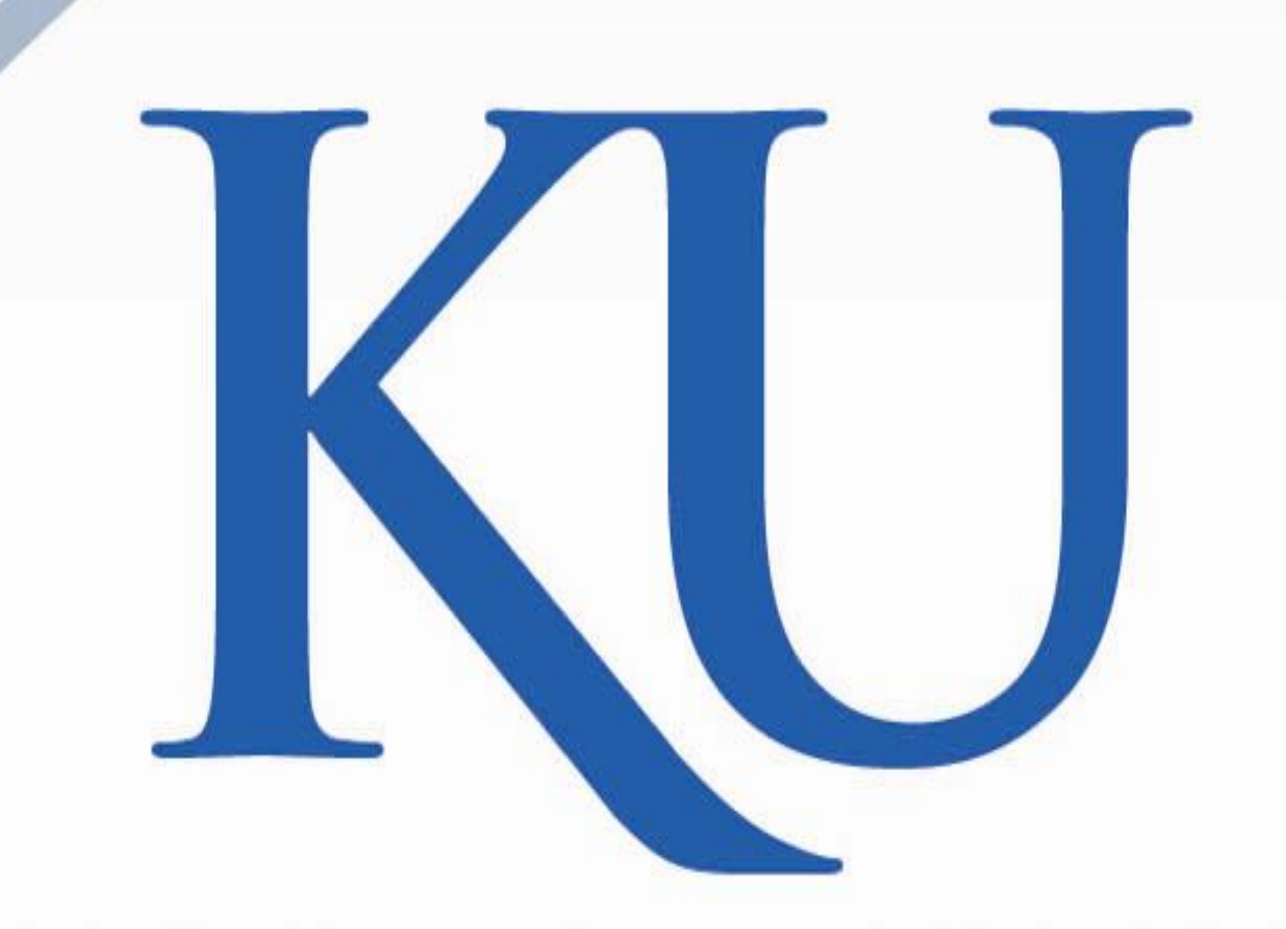

SCHOOL OF MEDICINE WICITIA

The University of Kansas 